\title{
Tetrel Bonds between Phenyltrifluorosilane and Dimethyl Sulfoxide: Influence of Basis Sets, Substitution and Competition
}

\author{
Xiulin An ${ }^{1}$, Xin Yang ${ }^{2}$ and Qingzhong $\mathrm{Li}^{2, *}$ \\ 1 College of Life Science, Yantai University, Yantai 264005, China; anxiulinli@sina.com \\ 2 The Laboratory of Theoretical and Computational Chemistry, School of Chemistry and Chemical Engineering, \\ Yantai University, Yantai 264005, China; yangx@ytu.edu.cn \\ * Correspondence: lqz@ytu.edu.cn
}

Citation: An, X.; Yang, X.; Li, Q. Tetrel Bonds between

Phenyltrifluorosilane and Dimethyl Sulfoxide: Influence of Basis Sets, Substitution and Competition. Molecules 2021, 26, 7231. https:// doi.org/10.3390/molecules26237231

Academic Editor: Ángel

Martín Pendás

Received: 6 November 2021

Accepted: 22 November 2021

Published: 29 November 2021

Publisher's Note: MDPI stays neutral with regard to jurisdictional claims in published maps and institutional affiliations.

Copyright: (C) 2021 by the authors. Licensee MDPI, Basel, Switzerland. This article is an open access article distributed under the terms and conditions of the Creative Commons Attribution (CC BY) license (https:/ / creativecommons.org/licenses/by/ $4.0 /)$.

\begin{abstract}
Ab initio calculations have been performed for the complexes of DMSO and phenyltrifluorosilane (PTS) and its derivatives with a substituent of $\mathrm{NH}_{3}, \mathrm{OCH}_{3}, \mathrm{CH}_{3}, \mathrm{OH}, \mathrm{F}, \mathrm{CHO}, \mathrm{CN}, \mathrm{NO}_{2}$, and $\mathrm{SO}_{3} \mathrm{H}$. It is necessary to use sufficiently flexible basis sets, such as aug'-cc-pVTZ, to get reliable results for the $\mathrm{Si} \cdots \mathrm{O}$ tetrel bonds. The tetrel bond in these complexes has been characterized in views of geometries, interaction energies, orbital interactions and topological parameters. The electrondonating group in PTS weakens this interaction and the electron-withdrawing group prominently strengthens it to the point where it exceeds that of the majority of hydrogen bonds. The largest interaction energy occurs in the $p-\mathrm{HO}_{3} \mathrm{~S}-\mathrm{PhSiF}_{3} \cdots \mathrm{DMSO}$ complex, amounting to $-122 \mathrm{~kJ} / \mathrm{mol}$. The strong $\mathrm{Si} \cdots \mathrm{O}$ tetrel bond depends to a large extent on the charge transfer from the $\mathrm{O}$ lone pair into the empty $p$ orbital of $\mathrm{Si}$, although it has a dominant electrostatic character. For the PTS derivatives of $\mathrm{NH}_{2}, \mathrm{OH}, \mathrm{CHO}$ and $\mathrm{NO}_{2}$, the hydrogen bonded complex is favorable to the tetrel bonded complex for the $\mathrm{NH}_{2}$ and $\mathrm{OH}$ derivatives, while the $\sigma$-hole interaction prefers the $\pi$-hole interaction for the $\mathrm{CHO}$ and $\mathrm{NO}_{2}$ derivatives.
\end{abstract}

Keywords: tetrel bonds; phenyltrifluorosilane; dimethyl sulfoxide; substituents; competition

\section{Introduction}

Recently, the tetrel bond has attracted more attention due to its potential applications in crystal materials [1-3], chemical reactions [4-6], and biological systems [7]. It is defined as an attractive interaction between a Group 14 atom and a Lewis base [1]. Like hydrogen bonds, the Lewis bases in tetrel bonds are usually nitrogen- and oxygen-containing molecules, though other types of Lewis bases are also found [8-11]. For example, this attractive interaction has been reported in some simple complexes of $\mathrm{SiF}_{4} \cdots \mathrm{NH}_{3}$ [12-14] and $\mathrm{SiF}_{4} \cdots \mathrm{H}_{2} \mathrm{O}$ [15]. However, this interaction was named a tetrel bond until 2013 [1]. Actually, the attractive interaction between a Group 14 atom and a Lewis base has been understood with molecular electrostatic potentials (MEPs), and it was found that there is a region with positive MEPs ( $\sigma$-hole) at the outer side of the tetrel atom [16]. Now, the tetrel bond has been accepted as a $\sigma$-hole interaction by many researchers. In most cases, the $\sigma$-hole on the tetrel atom enlarges in the order $\mathrm{C}<<\mathrm{Si}<\mathrm{Ge}<\mathrm{Sn}<\mathrm{Pb}$ due to the larger polarization and smaller electronegativity of the heavier tetrel atom [16].

The strength of tetrel bond is related to not only the nature of the tetrel atom but its substituents adjoined to it as well. Specifically, the electron-withdrawing group in the tetrel donor enlarges the $\sigma$-hole on the tetrel atom and thus strengthens tetrel bond. For example, the interaction energy is -2.6 and $-10.5 \mathrm{kcal} / \mathrm{mol}$ in the complexes of $\mathrm{SiH}_{4} \cdots \mathrm{NH}_{3}$ and $\mathrm{SiF}_{4} \cdots \mathrm{NH}_{3}$, respectively [12]. The strength of the tetrel bond can also be regulated by the cooperative effect between the tetrel bond and other interactions [17-30]. Such a cooperative effect is important in constructing crystal materials and maintaining the conformation of macromolecules. In our paper, we studied the modulation of protonation on the interaction mode and strength between pyridine- $\mathrm{TF}_{3}(\mathrm{~T}=$ tetrel $)$ and $\mathrm{NH}_{3}$ [31]. 
A F $\cdots \mathrm{H}$ hydrogen bond in the neutral complex pyridine- $\mathrm{CF}_{3} \cdots \mathrm{NH}_{3}$ is changed to be a tetrel bond in the protonated analogue. The protonation has a prominent enhancing effect on the strength of tetrel bonding, with an increase of interactions energy from -14 to $-30 \mathrm{kcal} / \mathrm{mol}$.

A focus was also paid on the competition between the tetrel bond and other interactions [9,17,32-34]. In $\mathrm{NCCH}_{3} \cdots \mathrm{CH}_{3}$ and $\mathrm{CNCH}_{3} \cdots \mathrm{CH}_{3}$ [9], the single-electron tetrel bond is formed between $\mathrm{NC} / \mathrm{CN}$ and the methyl radical; on the other hand, a C-H. $\cdots \mathrm{N} / \mathrm{C}$ hydrogen bond is also present. Both interactions have comparable interaction energies, thus there is competition in the formation of both hydrogen-bonded and single-electron tetrel-bonded complexes. $\mathrm{F}_{2} \mathrm{CX}(\mathrm{X}=\mathrm{Se}$ and $\mathrm{Te})$ can form a tetrel bond through the $\pi$-hole on the carbon atom and a chalcogen bond through the $\sigma$-hole on the chalcogen atom, respectively [17]. The results showed that $\mathrm{F}_{2} \mathrm{CSe}$ forms a stronger tetrel bond and $\mathrm{F}_{2} \mathrm{CTe}$ engages in a stronger chalcogen bond. Even so, there is competition between tetrel and chalcogen bonds. In complexes of DMSO and $\mathrm{TF}_{3} \mathrm{X}(\mathrm{T}=\mathrm{C}$ and $\mathrm{Si} ; \mathrm{X}=$ halogen) [32], $\mathrm{CF}_{3} \mathrm{X}$ is favorable to form the halogen-bonded complexes and $\mathrm{SiF}_{3} \mathrm{X}$ prefers the formation of the tetrel-bonded complexes. The halogen bond can compete with the tetrel bond in the complexes of $\mathrm{CF}_{3} \mathrm{X}$, whereas the tetrel bond dominates over the halogen bond in the complexes of $\mathrm{SiF}_{3} \mathrm{X}$. When $\mathrm{NH}_{3}$ approaches $\mathrm{XCN}(\mathrm{X}=\mathrm{F}, \mathrm{Cl}, \mathrm{Br}$, I) along its molecular axis or a perpendicular $\pi$-hole on the carbon atom, a $\sigma$-hole halogen bond and a $\pi$-hole tetrel bond are formed, respectively [33]. Moreover, the latter geometry is favored for $\mathrm{X}=\mathrm{F}$ and the $\sigma$-hole structure is preferred for the heavier halogens.

In the present paper, we study the tetrel bonded complex between phenyltrifluorosilane (PTS) and dimethyl sulfoxide (DMSO). PTS is an original and effective reagent and synthon in organoelemental and organic synthesis [35,36]. DMSO is a good solvent in chemical reactions and biological proceeds [37]. Thus, it is important to study the interaction between both molecules. First, a reliable basis set is considered for studying the tetrel bond between them. Then this tetrel bond is characterized in views of geometries, energies, orbital interactions and topological parameters. Thirdly, the substitution effect on the strength of the tetrel bond is investigated in the para-derivatives of PTS. Finally, the competition between the tetrel bond and other interactions is studied.

\section{Theoretical Methods}

The geometries of complexes and monomers were optimized at the second-order Møller-Plesset perturbation theory (MP2) level of theory with three basis sets including $6-311++G(d, p)$, aug-cc-pVDZ, and aug'-cc-pVTZ, which is the Dunning aug-cc-pVTZ basis set with diffuse functions removed from $\mathrm{H}$ atoms. Frequencies were computed with the former two basis sets to identify local minima on the surfaces. Optimization and frequency calculations were carried out using the Gaussian09 program [38].

Interaction energies were computed as the difference between the energy of complex and the sum of energy of monomer in the complex. Interaction energies were obtained with the above three basis sets and with the aug-cc-pVTZ and 6-311++G(3df,2p) basis sets on the MP2/6-311++G(d,p) geometries. Interaction energies were then corrected for the basis set superposition error (BSSE) by using the Boys-Bernardi counterpoise technique [39]. The similar theoretical methodology was also performed for other types of noncovalent interactions [40-44].

Molecular electrostatic potentials were derived via the wavefunction analysis-surface analysis suite (WFA-SAS) program [45] using the MP2/aug'-cc-pVTZ electron density. The Natural Bond Orbital (NBO) method [46] has been used to analyze the orbital interactions and charge transfer. Since MP2 orbitals are nonexistent, the second-order perturbation energies were evaluated using WB97XD method with the aug'-cc-pVTZ basis set on the MP2/aug'-cc-pVTZ geometries. The "atoms in molecules" (AIM) theory of Bader [47] was applied, and the bond critical points were analyzed in terms of electron densities, Laplacians and energy densities. The AIM calculations were performed with the use of the AIM2000 program [48]. 


\section{Results and Discussion}

\subsection{Selection of Basis Sets}

Figure 1 shows the scheme of ten complexes studied here. Table 1 presents the interaction energies of these complexes at the MP2 level with different basis sets including aug-cc-pVDZ, aug-cc-pVTZ, aug'-cc-pVTZ, 6-311++G(d,p) and 6-311++G(3df,2p). Dunning basis sets are often used in studying non-covalent interactions. Considering our systems are bigger, we firstly optimized these complexes with a small Dunning basis set aug-cc-pVDZ and the corresponding interaction energy is marked as $\Delta E_{1}$. Then we optimized these complexes with another type of basis set $6-311++G(d, p)$ and the corresponding interaction energy is represented as $\Delta E_{2}$.

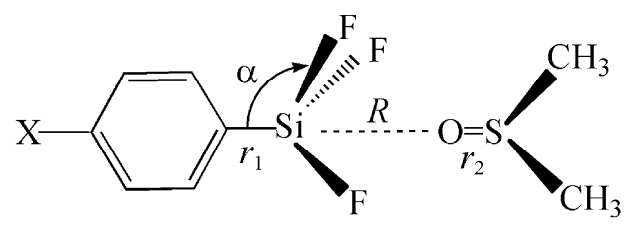
1. $\mathrm{X}=\mathrm{H}$
6. $\mathrm{X}=\mathrm{F}$
2. $\mathrm{X}=\mathrm{NH}_{2}$
7. $\mathrm{X}=\mathrm{CHO}$
3. $\mathrm{X}=\mathrm{OCH}_{3}$
8. $\mathrm{X}=\mathrm{CN}$
4. $\mathrm{X}=\mathrm{CH}_{3}$
9. $\mathrm{X}=\mathrm{NO}_{2}$
5. $\mathrm{X}=\mathrm{OH}$
10. $\mathrm{X}=\mathrm{SO}_{3} \mathrm{H}$

Figure 1. Scheme of tetrel bonded complexes.

Table 1. Interactions energies $(\Delta E, \mathrm{~kJ} / \mathrm{mol})$ at the levels of MP2/aug-cc-pVDZ/ $/ \mathrm{MP} 2 /$ aug-cc-pVDZ (1), MP2/6-311++G(d,p)//MP2/6-311++G(d,p) (2), MP2/aug-cc-pVTZ//MP2/6-311++G(d,p) (3), $\mathrm{MP} 2 / 6-311++\mathrm{G}(3 \mathrm{df}, 2 \mathrm{p}) / / \mathrm{MP} 2 / 6-311++\mathrm{G}(\mathrm{d}, \mathrm{p})(4)$, and MP2/aug'-cc-pVTZ//MP2/aug'-cc-pVTZ (5) in the ten complexes of $p-\mathrm{X}-\mathrm{PhSiF}_{3} \cdots \mathrm{DMSO}$.

\begin{tabular}{ccccccc}
\hline & $\mathbf{X}=$ & $\Delta \boldsymbol{E}_{\mathbf{1}}$ & $\boldsymbol{\Delta} \boldsymbol{E}_{\mathbf{2}}$ & $\boldsymbol{\Delta} \boldsymbol{E}_{\mathbf{3}}$ & $\boldsymbol{\Delta} \boldsymbol{E}_{\mathbf{4}}$ & $\boldsymbol{\Delta} \boldsymbol{E}_{\mathbf{5}}$ \\
\hline $\mathbf{1}$ & $\mathrm{H}$ & -16.62 & -15.41 & -22.07 & -19.58 & -18.87 \\
$\mathbf{2}$ & $\mathrm{NH}_{2}$ & -16.45 & -12.26 & -18.76 & -16.43 & -16.29 \\
$\mathbf{3}$ & $\mathrm{OCH}_{3}$ & -13.96 & -13.15 & -19.69 & -17.31 & -17.38 \\
$\mathbf{4}$ & $\mathrm{CH}_{3}$ & -112.42 & -13.06 & -19.66 & -17.31 & -17.89 \\
$\mathbf{5}$ & $\mathrm{OH}$ & -20.95 & -14.57 & -21.17 & -18.73 & -18.10 \\
$\mathbf{6}$ & $\mathrm{F}$ & -136.22 & -102.08 & -112.33 & -107.64 & -95.23 \\
$\mathbf{7}$ & $\mathrm{CHO}$ & -136.72 & -95.25 & -112.48 & -107.42 & -105.10 \\
$\mathbf{8}$ & $\mathrm{CN}$ & non & -116.59 & -135.46 & -130.46 & -119.10 \\
$\mathbf{9}$ & $\mathrm{NO}_{2}$ & -152.15 & -119.47 & -138.19 & -133.21 & -120.95 \\
$\mathbf{1 0}$ & $\mathrm{SO}_{3} \mathrm{H}$ & non & -119.00 & -137.67 & -132.56 & -122.51 \\
\hline
\end{tabular}

One can see from Table 1 that $\Delta E_{1}$ is $-112.42 \mathrm{~kJ} / \mathrm{mol}$ in 4 , which is much larger than $-16.62 \mathrm{~kJ} / \mathrm{mol}$ in $\mathbf{1}$. On the other hand, the aug-cc-pVDZ basis set brings out a much shorter $\mathrm{Si} \cdots \mathrm{O}$ separation $(2.0125 \AA)$ in 4 than that in $\mathbf{1}(2.8562 \AA)$. That is, the methyl substituent greatly enhances the tetrel bond. Obviously, this is not possible owing to the weak electron-donating ability of the methyl group. In addition, $\Delta E_{1}$ is almost equal in 6 and 7 , which is also inconsistent with the different electron-withdrawing ability of both $-\mathrm{F}$ and -CHO groups. More impossibly, the interaction energies in 6, 7 and 9 are much larger at the MP2/aug-cc-pVDZ level than those at the MP2/aug'-cc-pVTZ level. This shows that the small Dunning aug-cc-pVDZ basis set is sometimes not reliable in studying the $\mathrm{Si} \cdots \mathrm{O}$ tetrel bonds and it is cautious to use this basis set in studying tetrel bonds since this basis set could provide some erroneous information in the structures and energies for tetrel bonded complexes. 
For the 6-311++G(d,p) interaction energy, it is found that $\Delta E_{2}$ in 4 is smaller than that in $\mathbf{1}$, consistent with the weak electron-donating nature of the methyl group. However, the $-\mathrm{F}$ substituent results in a larger $\Delta E_{2}$ than the $-\mathrm{CHO}$ one and an almost equal $\Delta E_{2}$ is caused by $-\mathrm{NO}_{2}$ and $-\mathrm{SO}_{3} \mathrm{H}$ substituents. This result disagrees with the relative magnitude of electronwithdrawing ability of these substituents. Accordingly, we think that $6-311++\mathrm{G}(\mathrm{d}, \mathrm{p})$ basis set is also unsuitable to study the $\mathrm{Si}$... O tetrel bonds. To compensate the interaction energies of small 6-311++G(d,p) basis set in the above complexes, we calculated the interaction energies with the larger basis sets aug-cc-pVTZ and 6-311++G(3df,2p) on the MP2/6$311++\mathrm{G}(\mathrm{d}, \mathrm{p})$ geometries and the corresponding interaction energies are denoted as $\Delta E_{3}$ and $\Delta E_{4}$, respectively. As expected, the interaction energies with the larger basis sets are larger than those with the smaller ones. However, the interaction energies in the above complexes are not improved and even become almost equal in $\mathbf{6}$ and 7 with the two larger basis sets. Thus such correction for the interaction energy is not feasible.

It was demonstrated that MP2/aug-cc-pVTZ has often been used in studying tetrel bonded complexes $[9,17,32,34]$. However, this method is unpractical in large systems involving tetrel bonds owing to the computational cost and resource in our current condition. Based on the above results, these complexes were optimized at the MP2 level with aug'-cc-pVTZ basis set, in which the cc-pVTZ basis set is used for H atom. Importantly, MP2/aug'-cc-pVTZ method has successfully used to study many pnicogen bonded complexes [49-51]. Thus the following discussion is based on the MP2/aug'-cc-pVTZ results.

\subsection{Interaction Energies and Geometries}

The MP2/aug'-cc-pVTZ optimized structures are shown in Figure S1 (Supplementary Materials). Although these complexes are connected mainly by a tetrel bond, they show an observed difference in structures. For $\mathrm{X}=\mathrm{H}, \mathrm{NH}_{2}, \mathrm{OCH}_{3}, \mathrm{CH}_{3}$ and $\mathrm{OH}$, the $-\mathrm{SiF}_{3}$ group attacks the oxygen atom of DMSO along the inner side of both methyl groups. A reverse conformation is adopted for $\mathrm{X}=\mathrm{F}$. The $-\mathrm{SiF}_{3}$ group is introduced into the oxygen atom of DMSO along the direction of one methyl group when $\mathrm{X}=\mathrm{CHO}, \mathrm{CN}, \mathrm{NO}_{2}$, and $\mathrm{SO}_{3} \mathrm{H}$. Even so, we think that other interactions are very weak relative to the tetrel bond and do not change the tendency in stability of these complexes.

The interaction energy is calculated to be $-18.87 \mathrm{~kJ} / \mathrm{mol}$ in PTS...DMSO (1). Thus the tetrel bond in 1 belongs to a moderate interaction, having a comparable strength with the hydrogen bond in $\mathrm{H}_{2} \mathrm{O} \cdots \mathrm{H}_{2} \mathrm{O}$ (about $20 \mathrm{~kJ} / \mathrm{mol}$ at the MP2/CBS level [52]). This implies that the tetrel bond in $\mathbf{1}$ has an important effect on its structures and properties. The interaction energy in $\mathbf{1}$ is much smaller than that in $\mathrm{SiF}_{3} \mathrm{X} \cdots \mathrm{DMSO}(\mathrm{X}=$ halogen $)$, which is about $129-157 \mathrm{~kJ} / \mathrm{mol}$ [32]. The interaction energy is $-14.53 \mathrm{~kJ} / \mathrm{mol}$ in $\mathrm{PhSiH}_{3} \cdots \mathrm{DMSO}$ (Figure S2, Supplementary Materials), which is smaller than that in 1. This is attributed to the weak acidity of $\mathrm{Si}$ atom in $\mathrm{PhSiH}_{3}$, confirmed by the smaller $\sigma$-hole on the Si atom of $\mathrm{PhSiH}_{3}$. The dipole moment is 0.85 and $3.41 \mathrm{D}$ for $\mathrm{PhSiH}_{3}$ and $\mathrm{PhSiF}_{3}$, respectively. Thus polarization is also responsible for the larger interaction energy in $\mathbf{1}$ (Table S1, Supplementary Materials). The interaction energy is $-5.09 \mathrm{~kJ} / \mathrm{mol}$ in $\mathrm{PhCF}_{3} \cdots \mathrm{DMSO}$, much smaller than that in $\mathbf{1}$. The smaller $\sigma$-hole on the carbon atom and dipole moment $(3.10 \mathrm{D})$ of $\mathrm{PhCF}_{3}$ lead to the weaker tetrel bond in $\mathrm{PhCF}_{3} \ldots \mathrm{DMSO}$. The interaction energy is $\sim 3.34 \mathrm{~kJ} / \mathrm{mol}$ in $\mathrm{PhCF}_{3} \cdots \mathrm{Cl}^{-}$at the CCSD(T)/def2-TZVP level of theory [53], which is close to that in $\mathrm{PhCF}_{3} \ldots$ DMSO. This implies that like anions, DMSO has a strong affinity for the tetrel atom.

The para $\mathrm{H}$ atom of $\mathrm{PhSiF}_{3}$ can be replaced by various substituents including electrondonating groups $\left(\mathrm{NH}_{3}, \mathrm{OCH}_{3}, \mathrm{CH}_{3}\right.$, and $\left.\mathrm{OH}\right)$ and electron-withdrawing groups $(\mathrm{F}, \mathrm{CHO}$, $\mathrm{CN}, \mathrm{NO}_{2}$, and $\mathrm{SO}_{3} \mathrm{H}$ ). The interaction energy climbs from a minimum of $-16.29 \mathrm{~kJ} / \mathrm{mol}$ to $-122.51 \mathrm{~kJ} / \mathrm{mol}$ for the strongest $p-\mathrm{SO}_{3} \mathrm{H}-\mathrm{PhSiF}_{3}$ electron acceptor. As expected, the electron-donating groups weaken the tetrel bond and the electron-withdrawing groups enhance the tetrel bond. The weakening of tetrel bond varies in the order $\mathrm{OH}<\mathrm{CH}_{3}$ $<\mathrm{OCH}_{3}<\mathrm{NH}_{3}$, and the enhancing of tetrel bond is in the sequence $\mathrm{F}<\mathrm{CHO}<\mathrm{CN}<$ $\mathrm{NO}_{2}<\mathrm{SO}_{3} \mathrm{H}$. Moreover, the electron-donating groups have a small weakening effect on 
the strength of the tetrel bond, while the electron-withdrawing groups have a prominent enhancing effect on the strength of tetrel bond. For the electron-withdrawing groups, the interaction energy of the tetrel bond exceeds $-95 \mathrm{~kJ} / \mathrm{mol}$, corresponding to a very strong tetrel bond. This influence of electron-withdrawing substituents is much greater than that in halogen bonded pyridine complexes [54]. Moreover, any electron-withdrawing substituent in the aromatic tetrel bond donors can cause the prominent enhancement of the tetrel bond. A simple F substitution could realize this target and the interaction energy has a slight increase when the electron-withdrawing ability of a group exceeds that of $\mathrm{CN}$. Consequently, introducing an electron-withdrawing substituent in the aromatic tetrel bond donors is a very efficient method for strengthening tetrel bonds.

We have represented the Hammett's plot for the tetrel bonded complexes studied here. In Figure 2, we have plotted the interaction energies versus the aromatic substituent constant $(\delta)$ for the benzene complexes. A good degree of correlation is obtained for the electron-donating and electron-withdrawing substituents, respectively. Thus it can be concluded that the aromatic substituent constant $(\delta)$ can be used to measure trends in tetrel bonding stability. Interestingly, the slope of the regression plot in the electron-withdrawing substituents is greatly larger than that in the electron-donating substituents, indicating that the influence of the electron-withdrawing substituents on the interaction energy is bigger than that of the electron-donating substituents. In addition, the different regression plots for both electron-donating and electron-withdrawing substituents imply that the influence of the substituents on the interaction energies is caused by induction effects and that resonance effects are also important.

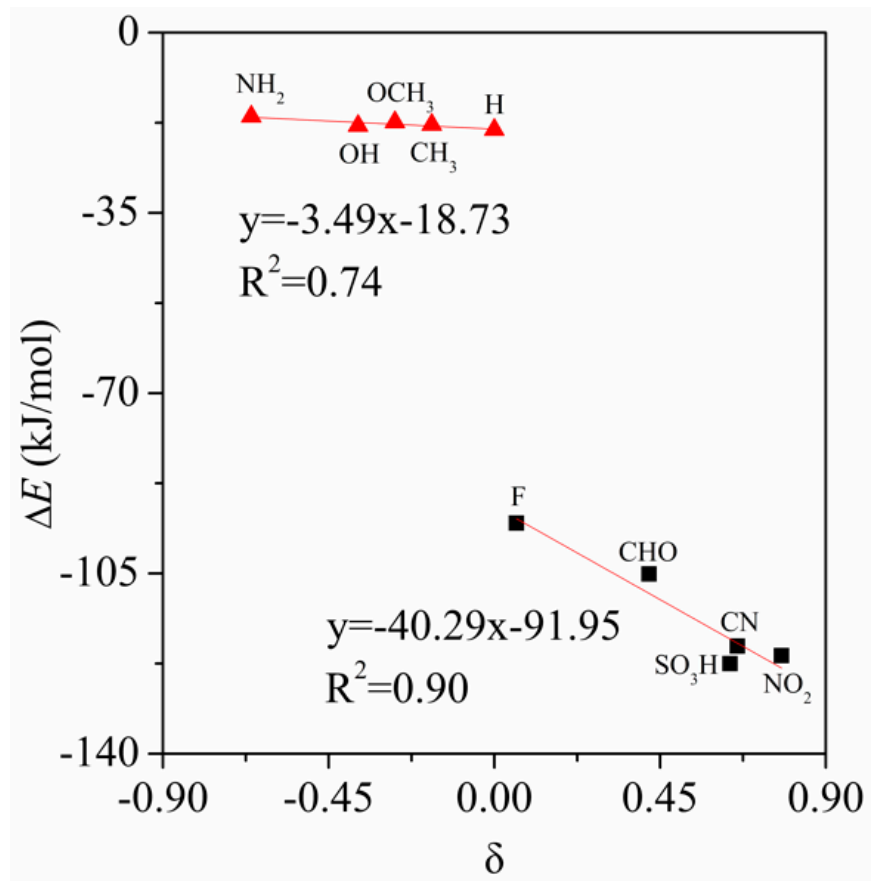

Figure 2. Hammett's plot of the tetrel bonded complexes.

To study the electrostatic nature of the tetrel bonding interaction in the aromatic complexes, we have computed the most positive MEP value of the $\sigma$-hole at the $\mathrm{C}-\mathrm{Si}$ end in the tetrel bond donors. These values are shown in Figure S3 (Supplementary Materials). Also we have represented the MEP values versus the interaction energies of the complexes in Figure 3. We have obtained a good relationship between the interaction energies of the complexes and the MEP values for the electron-donating and electron-withdrawing substituents, respectively. This result clearly indicates that the changes observed in the interaction energies of the complexes due to the different substituents are primarily caused by electrostatic effects. The dominant role of electrostatic interaction is also confirmed by the energy decomposition results (Table S1, Supplementary Materials). Moreover, the slope 
of the regression plot in the electron-withdrawing substituents is greatly larger than that in the electron-donating substituents, which is similar to that of the relationship between the interaction energy and Hammett constant (Figure 2).

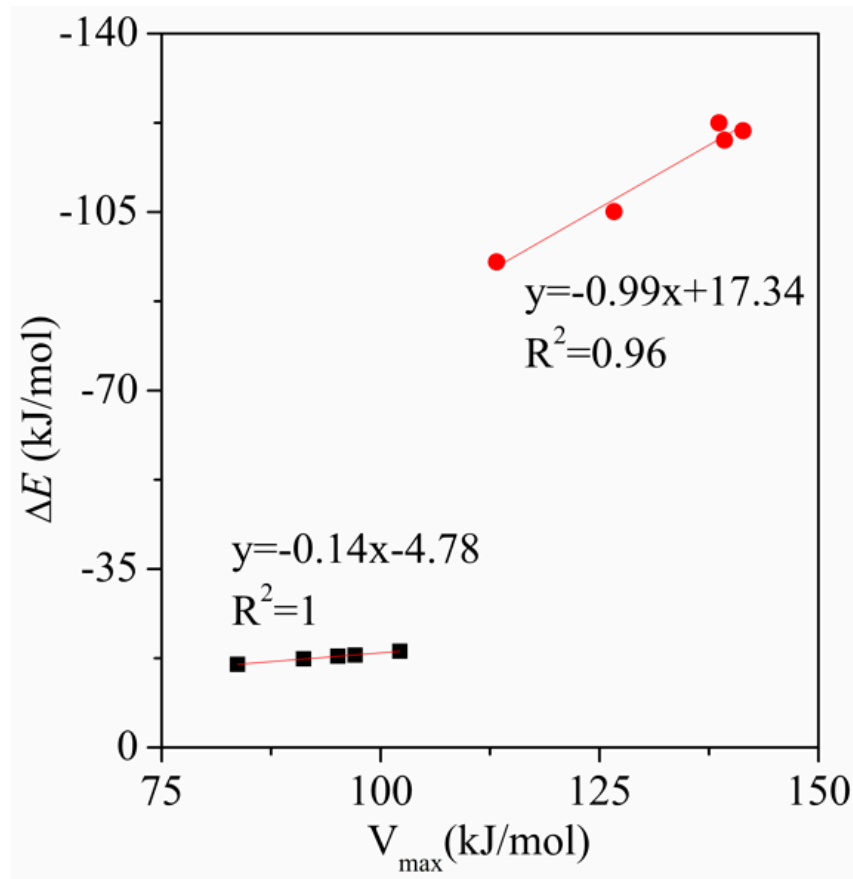

Figure 3. Regression plots of the interactions energy $(\Delta E)$ versus MEP value.

Table 2 presents the binding distance in the complexes. The binding distance comes down from a maximum of $3.00 \AA$ for the $-\mathrm{NH}_{2}$ substituent to $2.02 \AA$ for $-\mathrm{SO}_{3} \mathrm{H}$. It is much shorter than the sum of van der Waals Radii of Si and O atoms ( 3.6 $⿱$ ) [55]. A good quadratic relationship is found between the interaction energy and the $\mathrm{Si} \cdots \mathrm{O}$ separation (Figure 4). However, a linear relationship is usually present in hydrogen bonds [56]. This difference is mainly caused by the steric hindrance of three $\mathrm{F}$ atoms in the tetrel bonds. Along with this interaction strengthening, one sees a concomitant contraction of the intermolecular separation. Moreover, the interaction energy is more sensitive to the binding distance for the strong tetrel bonds. Namely, the small change of the binding distance in the range of the short $\mathrm{Si} \cdots \mathrm{O}$ separation corresponds to the large variation of the interaction energy.

Table 2. Binding distance $(R, \AA), \mathrm{C}-\mathrm{Si}$ bond length $\left(r_{1}, \AA\right)$, change of $\mathrm{C}-\mathrm{Si}(1)$ and $\mathrm{S}=\mathrm{O}(2)$ bond lengths $(\Delta r, \AA)$, and change of angle $\mathrm{C}-\mathrm{Si}-\mathrm{F}\left(\Delta \alpha\right.$, degree) in the complexes of $p-\mathrm{X}-\mathrm{PhSiF}_{3} \cdots \mathrm{DMSO}$.

\begin{tabular}{ccccccc}
\hline & $\mathbf{X}=$ & $\boldsymbol{R}$ & $\boldsymbol{r}_{\mathbf{1}}$ & $\boldsymbol{\Delta} \boldsymbol{r}_{\mathbf{1}}$ & $\boldsymbol{\Delta} \boldsymbol{r}_{\mathbf{2}}$ & $\boldsymbol{\Delta} \boldsymbol{\alpha}$ \\
\hline $\mathbf{1}$ & $\mathrm{H}$ & 2.9336 & 1.8453 & 0.0095 & 0.0035 & -3.0 \\
$\mathbf{2}$ & $\mathrm{NH}_{2}$ & 3.0032 & 1.8372 & 0.0088 & 0.0028 & -2.6 \\
$\mathbf{3}$ & $\mathrm{OCH}_{3}$ & 2.9740 & 1.8395 & 0.0090 & 0.0031 & -2.7 \\
$\mathbf{4}$ & $\mathrm{CH}_{3}$ & 2.9581 & 1.8429 & 0.0092 & 0.0032 & -2.8 \\
$\mathbf{5}$ & $\mathrm{OH}$ & 2.9566 & 1.8405 & 0.0093 & 0.0033 & -2.8 \\
$\mathbf{6}$ & $\mathrm{F}$ & 2.0996 & 1.8790 & 0.0439 & 0.0333 & -12.3 \\
$\mathbf{7}$ & $\mathrm{CHO}$ & 2.0715 & 1.8861 & 0.0460 & 0.0268 & -12.8 \\
$\mathbf{8}$ & $\mathrm{CN}$ & 2.0265 & 1.8910 & 0.0504 & 0.0384 & -13.4 \\
$\mathbf{9}$ & $\mathrm{NO}_{2}$ & 2.0221 & 1.8915 & 0.0501 & 0.0388 & -13.4 \\
$\mathbf{1 0}$ & $\mathrm{SO}_{3} \mathrm{H}$ & 2.0188 & 1.8926 & 0.0506 & 0.0392 & -13.5 \\
\hline
\end{tabular}




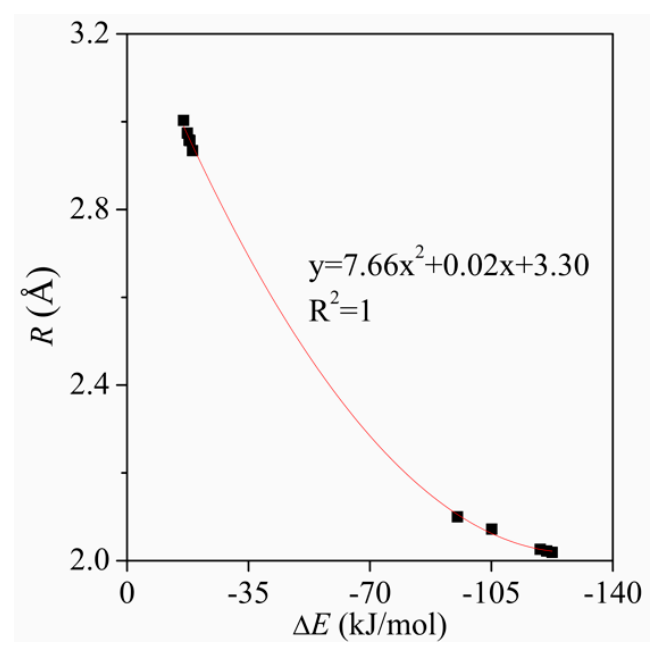

Figure 4. Regression plots of the interactions energy $(\Delta E)$ versus binding distance $(R)$.

The formation of tetrel bonds results in an elongation of $\mathrm{C}-\mathrm{Si}$ and $\mathrm{S}=\mathrm{O}$ bonds (Table 2). The elongation of $\mathrm{C}-\mathrm{Si}$ bond is greater than that of $\mathrm{S}=\mathrm{O}$ bond. A good linear relationship is found between the elongation of $\mathrm{C}-\mathrm{Si}$ bond and the interaction energy (Figure S4, Supplementary Materials). This indicates that the magnitude of $\mathrm{C}-\mathrm{Si}$ bond elongation can also be an indicator of tetrel bonding strength. The largest elongation of $\mathrm{C}-\mathrm{Si}$ bond amounts to about $0.05 \AA$ in $\mathbf{1 0}$. Generally, the elongation of the $\mathrm{S}=\mathrm{O}$ bond is also in close correspondence with the interaction energy (Figure S5, Supplementary Materials). The formation of the tetrel bond causes a deformation of the $-\mathrm{SiF}_{3}$ group, which can be estimated with the change of angle $\mathrm{C}-\mathrm{Si}-\mathrm{F}(\Delta \alpha)$ in the complex relative to the monomer. $\Delta \alpha$ is negative, indicating that there is a tendency to form a pentacoordinate silicon complex. The larger $\Delta \alpha$ corresponds to a stronger tetrel bond (Figure S6, Supplementary Materials).

The interaction energy increases by $-100 \mathrm{~kJ} / \mathrm{mol}$ due to the $-\mathrm{CN}$ substituent in the $\mathrm{PhSiF}_{3}$ complex. However, this substituent strengthens the tetrel bond by only $-5.73 \mathrm{~kJ} / \mathrm{mol}$ in the $\mathrm{PhSiH}_{3}$ complex (Figure S2, Supplementary Materials). The $-\mathrm{CN}$ substituent makes an increase of 37.07 and $35.32 \mathrm{~kJ} / \mathrm{mol}$ for the MEP of the $\sigma$-hole on the $\mathrm{Si}$ atom in $\mathrm{PhSiF}_{3}$ and $\mathrm{PhSiH}_{3}$, respectively. On the other hand, when the complex varies from $\mathrm{PhSiF}_{3} / \mathrm{PhSiH}_{3}$ to its $-\mathrm{CN}$ substituents, $\Delta \alpha$ is increased by about $10^{\circ}$ in the case of $\mathrm{PhSiF}_{3}$ but is almost not changed in the case of $\mathrm{PhSiH}_{3}$. This indicates that the deformation energy is also important in influencing the interaction energy of the tetrel bond by the electron-withdrawing substituent.

\subsection{NBO Analyses}

It has been demonstrated that charge transfer from the lone pair of a Lewis base into the $\mathrm{T}-\mathrm{X}$ anti-bonding orbital also stabilizes the tetrel bonded complexes of $\mathrm{TH}_{3} \mathrm{X}$ [7]. The similar orbital interaction of $\mathrm{Lp}_{\mathrm{O}} \rightarrow \sigma^{*} \mathrm{C}-\mathrm{Si}$ is also present in the $\mathrm{Si} \cdots \mathrm{O}$ tetrel bond of $p-\mathrm{X}-\mathrm{PhSiF}_{3} \cdots \mathrm{DMSO}$ complex. Interestingly, another important orbital interaction of $\mathrm{Lp} \mathrm{p}_{\mathrm{O}} \rightarrow p^{*} \mathrm{Si}$ is found in the $\mathrm{Si} \cdots \mathrm{O}$ tetrel bond. According to the corresponding secondorder perturbation energy in Table 3, one can see that the latter orbital interaction is far stronger than the former one in the $\mathrm{Si} \cdots \mathrm{O}$ tetrel bond. That is, the $\mathrm{Lp}_{\mathrm{O}} \rightarrow p^{*} \mathrm{Si}$ orbital interaction plays a more important role in stabilizing the strong $\mathrm{Si} \cdots \mathrm{O}$ tetrel bond than $\mathrm{Lp} \mathrm{P}_{\mathrm{O}} \rightarrow \sigma^{*} \mathrm{C}-\mathrm{Si}$. This is different from what is found in hydrogen bonding, where the lone pair charge is mainly transferred into the $\mathrm{H}-\mathrm{X}$ anti-bonding orbital [57], and in weak tetrel bonding, where the $\mathrm{Lp}_{\mathrm{O}} \rightarrow \sigma^{*} \mathrm{~T}-\mathrm{X}$ orbital interaction is dominant [7]. The presence of $\mathrm{Lp} \mathrm{P}_{\mathrm{O}} \rightarrow p^{*} \mathrm{Si}$ orbital interaction can be taken as a predictor of a strong tetrel bond with the formation of a partially covalent bond [32] and it is also used to explain the deformation of $-\mathrm{SiF}_{3}$ group in the complexes. The charge transfer from the lone pair of the oxygen atom to the $\mathrm{C}-\mathrm{Si}$ anti-bonding orbital is also reflected in the $\mathrm{C}-\mathrm{Si}$ bond elongation after complex formation although this charge transfer is small. The second-order perturbation 
energy due to the $\mathrm{L} \mathrm{p}_{\mathrm{O}} \rightarrow p^{*} \mathrm{Si}$ orbital interaction exhibits a good linear relationship with the interaction energy (Figure 5). The former is much larger in magnitude than the latter for the electron-withdrawing substituents. This result indicates that orbital interaction makes great contribution to the stabilization of strong tetrel bonded complexes. However, in the complexes with an electron-withdrawing substituent, the shorter $\mathrm{Si} \cdots \mathrm{O}$ separation brings out a big repulsive interaction (Table S1, Supplementary Materials), which could partly cancel the contribution of orbital interaction.

Table 3. Second-order perturbation energies $\left(E^{2}, \mathrm{~kJ} / \mathrm{mol}\right)$ due to the $\mathrm{Lp}_{\mathrm{O}} \rightarrow p^{*} \mathrm{Si}(1)$ and $\mathrm{Lp} \mathrm{p}_{\mathrm{O}} \rightarrow \sigma^{*} \mathrm{C}-\mathrm{Si}$ (2) orbital interactions and charge transferred $\left(\Delta q\right.$, e) from DMSO to $p-\mathrm{X}-\mathrm{PhSiF}_{3}$ fragment in the complexes of $p-\mathrm{X}-\mathrm{PhSiF}_{3} \cdots \mathrm{DMSO}$.

\begin{tabular}{ccccc}
\hline & $\mathbf{X}=$ & $\boldsymbol{E}^{\mathbf{2}} \mathbf{( 1 )}$ & $\boldsymbol{E}^{\mathbf{2}} \mathbf{( 2 )}$ & $\boldsymbol{\Delta} \boldsymbol{q}$ \\
\hline $\mathbf{1}$ & $\mathrm{H}$ & 23.70 & 2.76 & -0.0100 \\
$\mathbf{2}$ & $\mathrm{NH}_{2}$ & 18.85 & 2.30 & -0.0078 \\
$\mathbf{3}$ & $\mathrm{OCH}_{3}$ & 20.69 & 2.47 & -0.0086 \\
$\mathbf{4}$ & $\mathrm{CH}$ & 21.82 & 2.55 & -0.0092 \\
$\mathbf{5}$ & $\mathrm{OH}$ & 21.94 & 2.55 & -0.0092 \\
$\mathbf{6}$ & $\mathrm{F}$ & 469.04 & 20.06 & -0.1233 \\
$\mathbf{7}$ & $\mathrm{CHO}$ & 483.83 & 22.40 & -0.1329 \\
$\mathbf{8}$ & $\mathrm{CN}$ & 583.90 & 23.83 & -0.1440 \\
$\mathbf{9}$ & $\mathrm{NO}_{2}$ & 590.55 & 24.16 & -0.1455 \\
$\mathbf{1 0}$ & $\mathrm{SO}_{3} \mathrm{H}$ & 595.44 & 24.20 & -0.1465 \\
\hline
\end{tabular}

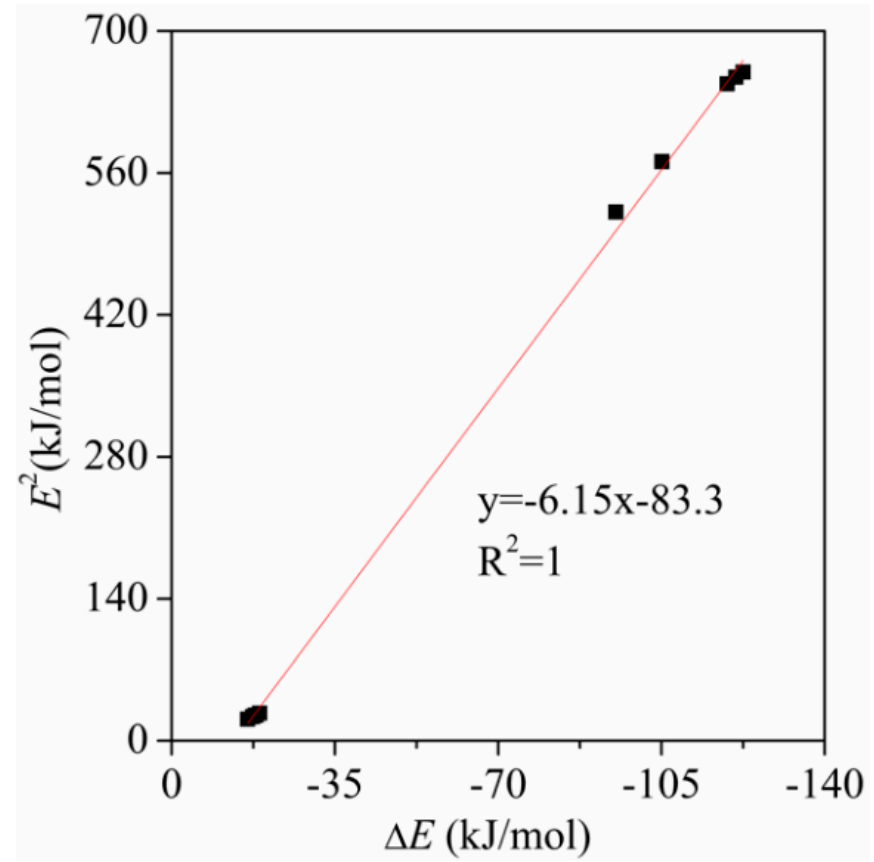

Figure 5. Regression plots of the interactions energy $(\Delta E)$ versus second-order perturbation energy $\left(E^{2}\right)$ due to the $\mathrm{Lp}_{\mathrm{O}} \rightarrow p^{*} \mathrm{Si}$ orbital interaction.

The charge transfer $(\Delta q)$ from the DMSO fragment to the $p-\mathrm{X}-\mathrm{PhSiF}$ fragment is also given in Table 3. $\Delta q<0$ shows that charge is transferred from the DMSO fragment to the $p-\mathrm{X}-\mathrm{PhSiF}_{3}$ fragment in the tetrel bond. $\Delta q$ is small $(<0.01 \mathrm{e})$ in the complexes with an electron-donating substituent but is very large $(>0.12 \mathrm{e})$ in the complexes with an electron-withdrawing substituent. The small $\Delta q$ supports the conclusion that electrostatic interaction is dominant in the weak $\mathrm{Si} \cdots \mathrm{O}$ interaction and the large $\Delta q$ is consistent with the fact that the strong $\mathrm{Si} \cdots \mathrm{O}$ tetrel bond has a nature of a partially covalent interaction.

There are also internal rearrangements within each monomer besides shifts from one molecule to another. The total electron density redistribution is displayed in Figure 6 
for four representative complexes, where purple regions represent charge buildup and depletion of density is indicated by blue. There is a common pattern in all of these complexes. Firstly, a small increase occurs on the oxygen lone pair of DMSO, accompanied with a larger area of charge loss immediately to the left of the Si atom. Buildup is also observed on the three $\mathrm{F}$ atoms of $-\mathrm{SiF}_{3}$ group. The $\mathrm{C}-\mathrm{Si}$ bond suffers a substantial loss of charge as indicated by the large blue area and this area is enlarged from the $-\mathrm{NH}_{2}$ to the $-\mathrm{CN}$ substituent.

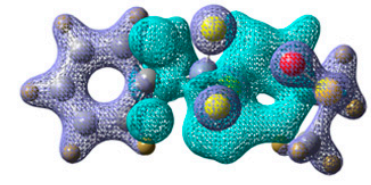

1

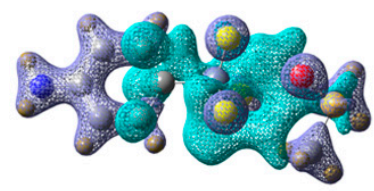

2

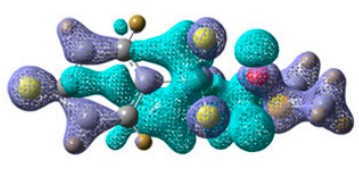

6

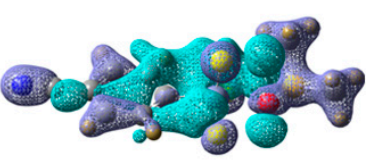

8

Figure 6. Density shifts occurring in the four tetrel bonded complexes of 1, 2, 6, and 8 upon formation of each complex. Purple regions indicate density increase, blue a decrease. Contours are shown at the 0.1 au level.

\subsection{AIM Analyses}

In the above analyses, we have pointed out that there exist other interactions between DMSO and $p-\mathrm{X}-\mathrm{PhSiF}_{3}$ and the strong tetrel bond in the complexes with an electronwithdrawing substituent exhibits a nature of partially covalent interaction. To confirm these, we performed an AIM analysis for these systems. Figure 7 shows the AIM bonding diagrams of three representative complexes. Interestingly, the tetrel bond is characterized by three $\mathrm{F} \cdots \mathrm{O}$ bond critical points (BCPs), not by a $\mathrm{Si} \cdots \mathrm{O}$ BCP. The similar result was also reported in $\mathrm{F}_{4} \mathrm{Si} \cdots \mathrm{NCH}$ complex [5]. Actually, there are some controversies and discussions on the physical meaning of the bond path term [58], although the bond paths show stabilizing and preferable interactions for the system being in the energetic minima [59]. Three $\mathrm{CH} \cdots \mathrm{F}$ BCPs are also found in $\mathbf{1}$, confirming the presence of $\mathrm{CH} \cdots \mathrm{F}$ interactions. The $\mathrm{H} \cdots \mathrm{F}$ separation $(\sim 2.5 \AA)$ in $\mathbf{1}$ is a little shorter than the sum of van der Waals Radii of $\mathrm{H}$ and $\mathrm{F}$ atoms $(\sim 2.67 \AA)$ [55]. The interaction energy of $\mathrm{CH} \cdots \mathrm{F}$ interaction is about $-2 \mathrm{~kJ} / \mathrm{mol}$ between two neutral molecules [60]. Thus we think that the $\mathrm{CH} \cdots \mathrm{F}$ interactions in $\mathbf{1}$ are weak and they have an insignificant effect on the strength of the tetrel bond although they play a role in maintaining the conformation of complex. The paths of the BCPs and the nature of $\mathrm{Si} \cdots \mathrm{O}$ tetrel bond in the complexes with the electron-donating group (2-5) are the same as those in 1 . The $\mathrm{Si} \cdots \mathrm{O}$ tetrel bond in $\mathbf{6}$ is characterized with the presence of a $\mathrm{Si} \cdots \mathrm{O}$ $\mathrm{BCP}$ and no other $\mathrm{BCPs}$ are found in 6 . The $\mathrm{Si} \cdots \mathrm{O} \mathrm{BCP}$ has the larger electron density and Laplacian in 6 than the F $\cdots \mathrm{O}$ BCP in $\mathbf{1}$. On the other hand, the energy density at the $\mathrm{Si} \cdots \mathrm{O}$ $\mathrm{BCP}$ is negative in 6 , indicating the partially covalent character of the $\mathrm{Si} \cdots \mathrm{O}$ tetrel bond [61]. The $\mathrm{Si} \cdots \mathrm{O}$ tetrel bond in 7 has the same $\mathrm{Si} \cdots \mathrm{O}$ BCP with the positive Laplacian and the negative energy density as that in 6 . Nevertheless, the electron density at the $\mathrm{Si} \cdots \mathrm{O}$ tetrel bond in 7 is a little larger than that in 6 , consistent with the strength of tetrel bond in both complexes. In addition, 7 has three similar intermolecular BCPs like 1 . In $\mathbf{9}$, there is a F ‥C $\mathrm{BCP}$ besides the $\mathrm{Si} \cdots \mathrm{O} \mathrm{BCP}$. The former $\mathrm{BCP}$ is also taken as a predictor of a F $\cdots \mathrm{C}$ tetrel bond. Similarly, the $\mathrm{Si} \cdots \mathrm{O}$ tetrel bond in 9 has the negative energy density but the larger electron density, corresponding to a stronger $\mathrm{Si} \cdots \mathrm{O}$ tetrel bond with a covalent character. The same paths of $\mathrm{Si} \cdots \mathrm{O}$ and $\mathrm{F} \cdots \mathrm{C}$ BCP are also found in $\mathbf{8}$ and $\mathbf{1 0 .}$ 


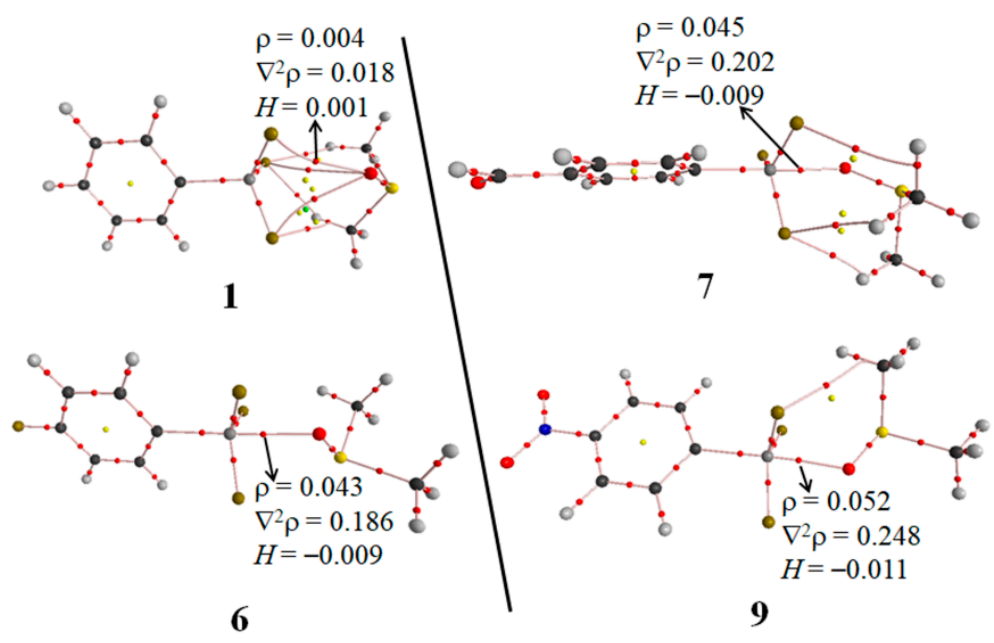

Figure 7. Molecular graph of the four tetrel bonded complexes of 1, 6, 7, and 9.

\subsection{Competition}

In the complexes of DMSO and $p-\mathrm{X}-\mathrm{PhSiF}_{3}\left(\mathrm{X}=\mathrm{NH}_{2}, \mathrm{OH}, \mathrm{CHO}\right.$, and $\left.\mathrm{NO}_{2}\right)$, there exist other interactions besides a tetrel bond. As expected, the proton of both $\mathrm{NH}_{2}$ and $\mathrm{OH}$ groups can form a hydrogen bond with the oxygen atom of DMSO. It is seen from Figure S3 (Supplementary Materials) that there is a $\pi$-hole on the carbon atom of $-\mathrm{CHO}$ and the nitrogen atom of $-\mathrm{NO}_{2}$, respectively. The $\pi$-hole is a region with positive MEPs that is perpendicular to an adjacent portion of the molecular framework [62]. Thus the oxygen atom of DMSO participates in the formation of both a $\pi$-hole tetrel bond with the carbon atom of $-\mathrm{CHO}$ and a $\pi$-hole pnicogen bond with the nitrogen atom of $-\mathrm{NO}_{2}$. The latter interaction has been evidenced in many complexes involving nitro compounds [63-65]. We have studied some $\pi$-hole tetrel bonds in the complexes of $F_{2} C X(X=S e$ and Te) $[17,66]$. However, no evidence is found for the $\pi$-hole tetrel bonds involving a formyl group. Figure 8 shows the AIM bonding diagrams of these complexes.

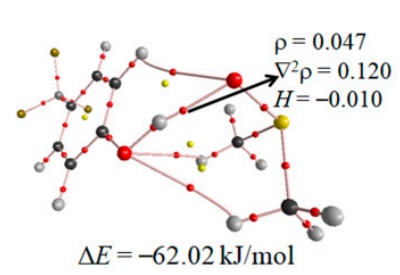

$p-\mathrm{SiF}_{3}-\mathrm{PhOH} \cdots \mathrm{DMSO}(\mathbf{1 1})$

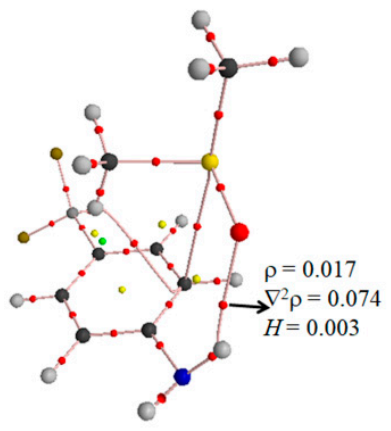

$\Delta E=-45.99 \mathrm{~kJ} / \mathrm{mol}$

$p-\mathrm{SiF}_{3}-\mathrm{PhNH}_{2} \cdots \mathrm{DMSO}(\mathbf{1 2})$

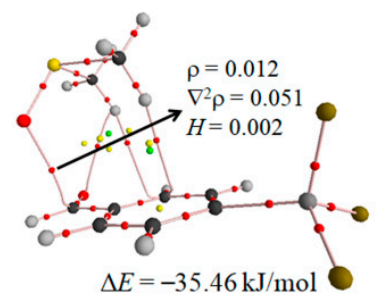

$p-\mathrm{SiF}_{3}-\mathrm{PhCHO} \cdots \mathrm{DMSO}(\mathbf{1 3})$

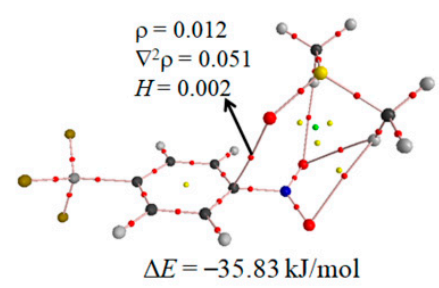

$p-\mathrm{SiF}_{3}-\mathrm{PhNO}_{2} \cdots \mathrm{DMSO}(\mathbf{1 4})$

Figure 8. Molecular graph of the complexes between $\mathrm{DMSO}$ and $p-\mathrm{SiF}_{3}-\mathrm{PhX}\left(\mathrm{X}=\mathrm{NH}_{2}, \mathrm{OH}, \mathrm{CHO}\right.$, and $\mathrm{NO}_{2}$ ). 
In $p-\mathrm{SiF}_{3}-\mathrm{PhOH} \cdots \mathrm{DMSO}(\mathbf{1 1})$, the conformation of the complex is similar to that of the most stable complex of DMSO and $\mathrm{H}_{2} \mathrm{O}$ [67], in which an $\mathrm{OH} \cdots \mathrm{O}$ hydrogen bond coexists with two $\mathrm{CH} \cdots \mathrm{O}$ interactions. Both $\mathrm{OH} \cdots \mathrm{O}$ hydrogen bond and $\mathrm{CH} \cdots \mathrm{O}$ interactions in 11 are characterized by an $\mathrm{OH} \cdots \mathrm{O} \mathrm{BCP}$ and a $\mathrm{CH} \cdots \mathrm{O} \mathrm{BCP}$, respectively. Additionally, a $\mathrm{CH} \cdots \mathrm{O} B C P$ is also found between the $\mathrm{C}-\mathrm{H}$ proton of the benzene ring and the oxygen atom of DMSO in 11. The energy density at the $\mathrm{OH} \cdots \mathrm{O}$ BCP in $\mathbf{1 1}$ is negative, indicating that this hydrogen bond has a partially covalent character [61]. Thus the $\mathrm{OH} \cdots \mathrm{O}$ hydrogen bond in $\mathbf{1 1}$ is stronger than that in the complex of DMSO and $\mathrm{H}_{2} \mathrm{O}$, consistent with the acidity of hydroxyl proton in both molecules of $p-\mathrm{HO}-\mathrm{PhSiF}_{3}$ and $\mathrm{H}_{2} \mathrm{O}$. The interaction energy is calculated to be $-62.02 \mathrm{~kJ} / \mathrm{mol}$ in 11, which is much larger than that in 5 . As a result, the oxygen atom of DMSO is favorable to bind with the hydroxyl proton of $p-\mathrm{HO}-\mathrm{PhSiF}_{3}$ than with the $-\mathrm{SiF}_{3}$ group.

In $p-\mathrm{SiF}_{3}-\mathrm{PhNH}_{2} \cdots \mathrm{DMSO}$ (12), the conformation of the complex is different from that in $\mathbf{1 1}$ since the nitrogen atom of $-\mathrm{NH}_{2}$ cannot again bind with two $\mathrm{C}-\mathrm{H}$ protons of DMSO simultaneously. The $\mathrm{NH} \cdots \mathrm{O}$ hydrogen bond is characterized by a $\mathrm{NH} \cdots \mathrm{O} \mathrm{BCP}$.

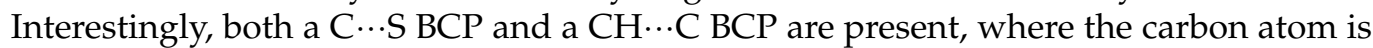
adjoined to the $-\mathrm{NH}_{2}$ group in the benzene ring. The energy density at the $\mathrm{NH} \cdots \mathrm{O} B C P$ is positive, implying an electrostatic domination in this interaction. The interaction energy in 12 is larger than that in 2, thus DMSO prefers to form a hydrogen bonded complex than a tetrel bonded complex with $p-\mathrm{H}_{2} \mathrm{~N}-\mathrm{PhSiF}_{3}$. The electron density at the $\mathrm{H} \cdots \mathrm{O}$ BCP shows that the $\mathrm{NH} \cdots \mathrm{O}$ hydrogen bond in $\mathbf{1 2}$ is weaker than the $\mathrm{OH} \cdots \mathrm{O}$ one in $\mathbf{1 1}$, confirming the fact that the proton of $-\mathrm{OH}$ has a larger acidity than that of $-\mathrm{NH}_{2}$ [68].

In $p-\mathrm{SiF}_{3}-\mathrm{PhCHO} \cdots \mathrm{DMSO}(13)$, there is a $\mathrm{C} \cdots \mathrm{O} \mathrm{BCP}$ between the carbon atom of $-\mathrm{CHO}$ and the oxygen atom of DMSO, corresponding to a $\pi$-hole tetrel bond. $\mathrm{A} \mathrm{CH} \cdots \mathrm{O}$ interaction is present between the hydrogen atom of DMSO and the oxygen atom of $-\mathrm{CHO}$, evidenced by a $\mathrm{CH} \cdots \mathrm{O} \mathrm{BCP}$. Its interaction energy is estimated to be $-4 \mathrm{~kJ} / \mathrm{mol}$ according to the formulas of $\Delta E=1 / 2 \times \mathrm{V}$, where $\mathrm{V}$ is the potential energy density at the $\mathrm{CH} \cdots \mathrm{O}$ $\mathrm{BCP}$ [69]. In addition, two $\mathrm{CH} \cdots \mathrm{C}$ BCPs are found between the hydrogen atom of DMSO and the carbon atom of benzene ring. Even so, we think that the $\pi$-hole tetrel bond is a dominant interaction in 13. Of course, other weak interactions are also important in maintaining the conformation of the complex. The interaction energy in $\mathbf{1 3}$ amounts to about a third of that of 7 , indicating that the $\sigma$-hole tetrel bonded complex is dominant over the $\pi$-hole tetrel bonded complex.

In $p-\mathrm{SiF}_{3}-\mathrm{PhNO}_{2} \cdots \mathrm{DMSO}(\mathbf{1 4})$, the $\pi$-hole pnicogen bond is characterized with the presence of a $\mathrm{C} \cdots \mathrm{O} \mathrm{BCP}$, where the carbon atom is connected with $-\mathrm{NO}_{2}$. Although the $\pi$-hole appears on the nitrogen atom of $-\mathrm{NO}_{2}$, no bond path is found between the nitrogen atom of $-\mathrm{NO}_{2}$ and the oxygen atom of DMSO. This is different from the $\pi$-hole pnicogen bonded complexes between nitryl derivatives $\left(\mathrm{NO}_{2} \mathrm{X}, \mathrm{X}=\mathrm{CN}, \mathrm{F}, \mathrm{Cl}, \mathrm{Br}, \mathrm{NO}_{2}, \mathrm{OH}, \mathrm{CCH}\right.$, and $\left.\mathrm{C}_{2} \mathrm{H}_{3}\right)$ and molecules acting as Lewis bases $\left(\mathrm{H}_{2} \mathrm{O}, \mathrm{H}_{3} \mathrm{~N}, \mathrm{CO}, \mathrm{HCN}, \mathrm{HNC}\right.$ and $\left.\mathrm{HCCH}\right)$, where a $\mathrm{BCP}$ is associated with a bond path between the nitrogen atom of the nitryl derivative and one of the atoms of the electron donor molecule [65]. Besides, three $\mathrm{CH} \cdots \mathrm{O}$ $\mathrm{BCPs}$ are found between the hydrogen atom of DMSO and the oxygen atom of $-\mathrm{NO}_{2}$. The interaction energy is $-35.83 \mathrm{~kJ} / \mathrm{mol}$ in $\mathbf{1 4}$, which is less than a third of that in $\mathbf{9}$. This means that the $\sigma$-hole tetrel bonded complex is more stable than the $\pi$-hole pnicogen bonded complex. The interaction energy of $\pi$-hole pnicogen bond varied from $-4.7 \mathrm{~kJ} / \mathrm{mol}$ in $\mathrm{NO}_{2} \mathrm{OH} \cdots \mathrm{CO}$ to $-22.1 \mathrm{~kJ} / \mathrm{mol}$ in $\mathrm{NO}_{2} \mathrm{NO}_{2} \cdots \mathrm{NH}_{3}$ [65]. We think that the interaction energy of $\pi$-hole pnicogen bond in $\mathbf{1 4}$ is also within this range, and this conclusion is confirmed by the small electron density and the positive energy density at the $\mathrm{C} \cdots \mathrm{O} \mathrm{BCP}$.

To unveil the role of the $-\mathrm{SiF}_{3}$ group in the above interactions, we also studied the complexes of DMSO and $\mathrm{PhX}\left(\mathrm{X}=\mathrm{NH}_{2}, \mathrm{OH}, \mathrm{CHO}, \mathrm{NO}_{2}\right)$ by replacing this group with a hydrogen atom. As expected, their structures are similar to those of $p-\mathrm{SiF}_{3}-\mathrm{PhX} \cdots \mathrm{DMSO}$. The interaction energies are $-42.32,-56.89,-32.03$, and $-31.69 \mathrm{~kJ} / \mathrm{mol}$ for $\mathrm{X}=\mathrm{NH}_{2}, \mathrm{OH}$, $\mathrm{CHO}$, and $\mathrm{NO}_{2}$, respectively. Obviously, they are smaller than those in the corresponding 
complexes of $p-\mathrm{SiF}_{3}-\mathrm{PhX}$. Accordingly, the $-\mathrm{SiF}_{3}$ group in the benzene ring plays an electronwithdrawing role in the above interactions.

\section{Conclusions}

The complexes of DMSO and $p-\mathrm{X}-\mathrm{PhSiF}_{3}\left(\mathrm{X}=\mathrm{H}, \mathrm{NH}_{3}, \mathrm{OCH}_{3}, \mathrm{CH}_{3}, \mathrm{OH}, \mathrm{F}, \mathrm{CHO}, \mathrm{CN}\right.$, $\mathrm{NO}_{2}$, and $\mathrm{SO}_{3} \mathrm{H}$ ) have been investigated in views of the structures, energies, $\mathrm{NBO}$, and AIM. The following conclusions have been reached.

The basis set has an important influence on the structures and interaction energies of $\mathrm{Si} \cdots \mathrm{O}$ tetrel bonded complexes. It is necessary to use sufficiently flexible basis sets, such as aug'-cc-pVTZ, to get reliable results for the $\mathrm{Si} \cdots \mathrm{O}$ tetrel bonds.

The interaction energy of the $\mathrm{Si} \cdots \mathrm{O}$ tetrel bond varies in a wide range from the $-\mathrm{NH}_{2}$ $(-16.29 \mathrm{~kJ} / \mathrm{mol})$ to the $-\mathrm{SO}_{3} \mathrm{H}$ group $(-122.51 \mathrm{~kJ} / \mathrm{mol})$. The effect of the substituents in the tetrel bonded complexes follows the expected trend. Namely, this complex is favoured when an electron-withdrawing group occurs in the tetrel donor but an opposite result is obtained for the electron-donating substituent. Moreover, the weakening effect of the electron-donating substituent is trifling, while the enhancing impact of the electronwithdrawing group is wondrously prominent.

The substituents can also affect the nature of the $\mathrm{Si} \cdots \mathrm{O}$ tetrel bond. The $\mathrm{Si} \cdots \mathrm{O}$ tetrel bond is dominated by the electrostatic interaction in the complexes with the electrondonating substituent, while it has some degree of covalent character in the complexes with the electron-withdrawing group.

A strong linear relationship is established between the interaction energy and the Hammett's constant for the electron-donating and electron-withdrawing substituents, respectively. The MEP value on the $\sigma$-hole of the $\mathrm{Si}$ atom in $p-\mathrm{X}-\mathrm{PhSiF}_{3}$ strongly correlates with the interaction energies of the complexes for the electron-donating and electronwithdrawing substituents, respectively. This implies that deformation energy mainly caused by the formation of the partially covalent interaction is crucial in the strong $\mathrm{Si} \cdots \mathrm{O}$ tetrel bonds.

There is competition between the $\mathrm{Si} \cdots \mathrm{O}$ tetrel bond and another interaction in the complexes of DMSO and $p-\mathrm{X}-\mathrm{PhSiF}_{3}\left(\mathrm{X}=\mathrm{NH}_{2}, \mathrm{OH}, \mathrm{CHO}\right.$, and $\left.\mathrm{NO}_{2}\right)$. The hydrogen bonded complexes are more stable than the $\mathrm{Si} \cdots \mathrm{O}$ tetrel bonded ones for $\mathrm{X}=\mathrm{NH}_{2}$ and $\mathrm{OH}$, while the $\sigma$-hole tetrel bond prefers the $\pi$-hole interaction for $\mathrm{X}=\mathrm{CHO}$ and $\mathrm{NO}_{2}$.

Supplementary Materials: The following are available online, Table S1. Electrostatic energy ( $\left.E^{\text {ele }}\right)$, exchange energy $\left(E^{e x}\right)$, repulsion energy $\left(E^{r e p}\right)$, polarization energy $\left(E^{p o l}\right)$, and dispersion energy $\left(E^{\text {disp }}\right)$ in the complexes at the MP2/aug-cc-pVDZ level. All are in kJ/mol; Figure S1. Optimized structures of complexes p-X-PhSiF ${ }_{3} \cdots$ DMSO at the MP2/aug'-cc-pVTZ level; Figure S2. Optimized structures of complexes $\mathrm{PhSiH}_{3} \cdots \mathrm{DMSO}, \mathrm{PhCF}_{3} \cdots \mathrm{DMSO}$ and $p-\mathrm{NC}-\mathrm{PhSiH}_{3} \cdots \mathrm{DMSO}$ at the MP2/aug'-cc-pVTZ level; Figure S3. MEP maps of $p-X-\mathrm{PhSiF}_{3}\left(1: \mathrm{X}=\mathrm{H}, 2: \mathrm{X}=\mathrm{NH}_{2}, 3: \mathrm{X}=\mathrm{OCH}_{3}, 4: \mathrm{X}=\mathrm{CH}_{3}, 5: \mathrm{X}=\mathrm{OH}\right.$, 6: $\left.\mathrm{X}=\mathrm{F}, 7: \mathrm{X}=\mathrm{CHO}, 8: \mathrm{X}=\mathrm{CN}, 9: \mathrm{X}=\mathrm{NO}_{2}, 10: \mathrm{X}=\mathrm{SO}_{3} \mathrm{H}\right)$; Figure S4. Elongation of C-Si bond $\left(\Delta r_{\mathrm{C}-\mathrm{Si}}\right)$ versus the interaction energy $(\Delta E)$ in the complexes $p-\mathrm{X}-\mathrm{PhSiF}_{3} \cdots \mathrm{DMSO}$; Figure S5. Elongation of $\mathrm{S}=\mathrm{O}$ bond $\left(\Delta r_{\mathrm{S}=\mathrm{O}}\right)$ versus the interaction energy $(\Delta E)$ in the complexes $p-\mathrm{X}-\mathrm{PhSiF}{ }_{3} \cdots \mathrm{DMSO}$; Figure $\mathrm{S} 6$. Change of angle C-Si-F $(\Delta \alpha)$ versus the interaction energy $(\Delta E)$ in the complexes $p-\mathrm{X}-\mathrm{PhSiF} \mathrm{F}_{3} \cdots \mathrm{DMSO}$; cartesian coordinates of complexes.

Author Contributions: Q.L. conceived of the idea for this project and wrote a first draft of the manuscript; X.A. carried out the calculations and compiled the data; X.Y. supervised the calculations and helped with a final draft. All authors have read and agreed to the published version of the manuscript.

Funding: This research was funded by the National Natural Science Foundation of China grant number (21573188).

Institutional Review Board Statement: Not applicable.

Informed Consent Statement: Not applicable.

Data Availability Statement: Not applicable. 
Conflicts of Interest: The author declares no conflict of interest.

Sample Availability: Not applicable.

\section{References}

1. Bauzá, A.; Mooibroek, T.J.; Frontera, A. Tetrel-bonding interaction: Rediscovered supramolecular force? Angew. Chem. Int. Ed. 2013, 52, 12317-12321. [CrossRef] [PubMed]

2. Mahmoudi, G.; Bauzá, A.; Amini, M.; Molins, E.; Mague, J.T.; Frontera, A. On the importance of tetrel bonding interactions in lead (II) complexes with (iso) nicotinohydrazide based ligands and several anions. Dalton Trans. 2016, 45, 10708-10716. [CrossRef] [PubMed]

3. Gargari, M.S.; Stilinović, V.; Bauzá, A.; Frontera, A.; McArdle, P.; Derveer, D.V.; Ng, S.W.; Mahmoudi, G. Design of lead (II) metal-organic frameworks based on covalent and tetrel bonding. Chem. Eur. J. 2015, 21, 17951-17958. [CrossRef]

4. Mikosch, J.; Trippel, S.; Eichhorn, C.; Otto, R.; Lourderaj, U.; Zhang, J.X.; Hase, W.L.; Weidemüller, M.; Wester, R. Imaging nucleophilic substitution dynamics. Science 2008, 319, 183-186. [CrossRef] [PubMed]

5. Grabowski, S.J. Tetrel bond- $\sigma$-hole bond as a preliminary stage of the $\mathrm{S}_{\mathrm{N}} 2$ reaction. Phys. Chem. Chem. Phys. 2014, 16, 1824-1834. [CrossRef]

6. Liu, M.X.; Li, Q.Z.; Cheng, J.B.; Li, W.Z.; Li, H.B. Tetrel bond of pseudohalide anions with $\mathrm{XH}_{3} \mathrm{~F}(\mathrm{X}=\mathrm{C}, \mathrm{Si}, \mathrm{Ge}$, and Sn) and its role in $\mathrm{S}_{\mathrm{N}} 2$ reaction. J. Chem. Phys. 2016, 145, 224310. [CrossRef] [PubMed]

7. Mani, D.; Arunan, E. The $\mathrm{X}-\mathrm{C} \cdots \mathrm{Y}(\mathrm{X}=\mathrm{O} / \mathrm{F}, \mathrm{Y}=\mathrm{O} / \mathrm{S} / \mathrm{F} / \mathrm{Cl} / \mathrm{Br} / \mathrm{N} / \mathrm{P})$ 'carbon bond' and hydrophobic interactions. Phys. Chem. Chem. Phys. 2013, 15, 14377-14383. [CrossRef]

8. Mani, D.; Arunan, E. The $\mathrm{X}-\mathrm{C} \cdots \pi(\mathrm{X}=\mathrm{F}, \mathrm{Cl}, \mathrm{Br}, \mathrm{CN})$ carbon bond. J. Phys. Chem. A 2014, 118, 10081-10089. [CrossRef]

9. Li, Q.Z.; Guo, X.; Yang, X.; Li, W.Z.; Cheng, J.B.; Li, H.B. A $\sigma$-hole interaction with radical species as electron donors: Does single-electron tetrel bonding exist? Phys. Chem. Chem. Phys. 2014, 16, 11617-11625. [CrossRef]

10. Li, Q.Z.; Zhuo, H.Y.; Li, H.B.; Liu, Z.B.; Li, W.Z.; Cheng, J.B. Tetrel-hydride interaction between $\mathrm{XH}_{3} \mathrm{~F}(\mathrm{X}=\mathrm{C}, \mathrm{Si}, \mathrm{Ge}, \mathrm{Sn})$ and $\mathrm{HM}$ (M = Li, Na, BeH, MgH). J. Phys. Chem. A 2015, 119, 2217-2224. [CrossRef]

11. Liu, M.X.; Li, Q.Z.; Li, W.Z.; Cheng, J.B. Carbene tetrel-bonded complexes. Struct. Chem. 2017, 28, 823-831. [CrossRef]

12. Rossi, A.R.; Jasinski, J.M. Theoretical studies of neutral silane-ammonia adducts. Chem. Phys. Lett. 1990, 169, 399-404. [CrossRef]

13. Ruoff, R.S.; Emilsson, T.; Jaman, A.I.; Germann, T.C.; Gutowsky, H.S. Rotational spectra, dipole moment, and structure of the $\mathrm{SiF}_{4}-\mathrm{NH}_{3}$ dimer. J. Chem. Phys. 1992, 96, 3441-3446. [CrossRef]

14. Keith, T.A.; Bader, R.F.W. Origin of dipole moment enhancement in the formation of $\mathrm{SiF}_{4}-\mathrm{NH}_{3}$ dimer. J. Chem. Phys. 1992, 96, 3447-3451. [CrossRef]

15. Ignatov, S.K.; Sennikov, P.G.; Ault, B.S.; Bagatur'yants, A.A.; Simdyanov, I.V.; Razuvaev, A.G.; Klimov, E.J.; Gropen, O. Water complexes and hydrolysis of silicon tetrafluoride in the gas phase: An ab initio study. J. Phys. Chem. A 1999, 103, 8328-8336. [CrossRef]

16. Murray, J.S.; Lane, P.; Politzer, P. Expansion of the $\sigma$-hole concept. J. Mol. Model. 2009, 15, 723-729. [CrossRef]

17. Guo, X.; Liu, Y.W.; Li, Q.Z.; Li, W.Z.; Cheng, J.B. Competition and cooperativity between tetrel bond and chalcogen bond in complexes involving $\mathrm{F}_{2} \mathrm{CX}(\mathrm{X}=\mathrm{Se}$ and Te). Chem. Phys. Lett. 2015, 620, 7-12. [CrossRef]

18. Liu, M.X.; Li, Q.Z.; Li, W.Z.; Cheng, J.B. Tetrel bonds between $\mathrm{PySiX}_{3}$ and some nitrogenated bases: Hybridization, substitution, and cooperativity. J. Mol. Graph. Model. 2016, 65, 35-42. [CrossRef]

19. Liu, M.X.; Yang, L.; Li, Q.Z.; Li, W.Z.; Cheng, J.B.; Xiao, B.; Yu, X.F. Modulating the strength of tetrel bonding through beryllium bonding. J. Mol. Model. 2016, 22, 192. [CrossRef]

20. Tang, Q.J.; Li, Q.Z. Interplay between tetrel bonding and hydrogen bonding interactions in complexes involving $\mathrm{F}_{2} \mathrm{XO}(\mathrm{X}=\mathrm{C}$ and Si) and HCN. Comput. Theor. Chem. 2014, 1050, 51-57. [CrossRef]

21. McDowell, S.A.C. Sigma-hole cooperativity in anionic $\left[\mathrm{FX} \cdots \mathrm{CH}_{3} \cdots \mathrm{YF}\right]^{-}(\mathrm{X}, \mathrm{Y}=\mathrm{Cl}, \mathrm{Br})$ complexes. Chem. Phys. Lett. 2014, 598, 1-4. [CrossRef]

22. Esrafili, M.D.; Mohammadirad, N.; Solimannejad, M. Tetrel bond cooperativity in open-chain $\left(\mathrm{CH}_{3} \mathrm{CN}\right)_{\mathrm{n}}$ and $\left(\mathrm{CH}_{3} \mathrm{NC}\right)_{\mathrm{n}}$ clusters ( $\mathrm{n}=2-7)$ : An ab initio study. Chem. Phys. Lett. 2015, 628, 16-20. [CrossRef]

23. Solimannejad, M.; Orojloo, M.; Amani, S.J. Effect of cooperativity in lithium bonding on the strength of halogen bonding and tetrel bonding: $(\mathrm{LiCN})_{n} \cdots \mathrm{ClYF}_{3}$ and $(\mathrm{LiCN})_{\mathrm{n}} \cdots \mathrm{YF}_{3} \mathrm{Cl}(\mathrm{Y}=\mathrm{C}, \mathrm{Si}$ and $\mathrm{n}=1-5)$ complexes as a working model. Mol. Model. 2015, 21, 183. [CrossRef]

24. Yourdkhani, S.; Korona, T.; Hadipour, N.L. Interplay between tetrel and triel bonds in $\mathrm{RC}_{6} \mathrm{H}_{4} \mathrm{CN} \cdots \mathrm{MF}_{3} \mathrm{CN} \cdots \mathrm{BX}_{3}$ complexes: A combined symmetry-adapted perturbation theory, Møller-Plesset, and quantum theory of atoms-in-molecules study. J. Comput. Chem. 2015, 36, 2412-2428. [CrossRef]

25. Marín-Luna, M.; Alkorta, I.; Elguero, J. Cooperativity in tetrel bonds. J. Phys. Chem. A 2016, 120, 648-656. [CrossRef]

26. Esrafili, M.D.; Nurazar, R.; Mohammadian-Sabet, F. Cooperative effects between tetrel bond and other $\sigma-$ hole bond interactions: A comparative investigation. Mol. Phys. 2015, 113, 3703-3711. [CrossRef]

27. Esrafili, M.D.; Mohammadian-Sabet, F. Cooperativity of tetrel bonds tuned by substituent effects. Mol. Phys. 2016, 114, 1528-1538. [CrossRef]

28. Esrafili, M.D.; Mohammadian-Sabet, F. Tuning tetrel bonds via cation- $\pi$ interactions: An ab initio study on concerted interaction in $\mathrm{M}^{+}-\mathrm{C}_{6} \mathrm{H}_{5} \mathrm{XH}_{3}-\mathrm{NCY}$ complexes $(\mathrm{M}=\mathrm{Li}, \mathrm{Na}, \mathrm{K}$.; $\mathrm{X}=\mathrm{Si}, \mathrm{Ge} ; \mathrm{Y}=\mathrm{H}, \mathrm{F}, \mathrm{OH})$. Mol. Phys. 2016, 114, 83-91. [CrossRef] 
29. Rezaei, Z.; Solimannejad, M.; Esrafili, M.D. Interplay between hydrogen bond and single-electron tetrel bond: $\mathrm{H}_{3} \mathrm{C} \cdot \ldots \mathrm{COX}_{2} \cdots$ $\mathrm{HY}$ and $\mathrm{H}_{3} \mathrm{C} \cdots \mathrm{CSX}_{2} \cdots \mathrm{HY}(\mathrm{X}=\mathrm{F}, \mathrm{Cl} ; \mathrm{Y}=\mathrm{CN}, \mathrm{NC})$ complexes as a working model. Comput. Theor. Chem. 2015, 1074, 101-106. [CrossRef]

30. Vatanparast, M.; Parvini, E.; Bahadori, A. Computational study of the cooperative effects between tetrel bond and halogen bond in $\mathrm{XCN} \cdots \mathrm{F}_{2} \mathrm{CO} \cdots \mathrm{YCN}$ complexes $(\mathrm{X}=\mathrm{H}, \mathrm{F}, \mathrm{Cl}, \mathrm{Br} ; \mathrm{Y}=\mathrm{F}, \mathrm{Cl}, \mathrm{Br})$. Mol. Phys. 2016, 114, 1478-1484. [CrossRef]

31. Liu, M.X.; Li, Q.Z.; Scheiner, S. Comparison of tetrel bonds in neutral and protonated complexes of pyridineTF $\mathrm{Pand} \mathrm{furanTF}_{3}$ ( $\mathrm{T}=\mathrm{C}, \mathrm{Si}$, and $\mathrm{Ge}$ ) with $\mathrm{NH}_{3}$. Phys. Chem. Chem. Phys. 2017, 19, 5550-5559. [CrossRef]

32. Wei, Q.C.; Li, Q.Z.; Cheng, J.B.; Li, W.Z.; Li, H.B. Comparison of tetrel bonds and halogen bonds in complexes of DMSO with $\mathrm{ZF}_{3} \mathrm{X}(\mathrm{Z}=\mathrm{C}$ and $\mathrm{Si} ; \mathrm{X}=$ halogen $)$. RSC Adv. 2016, 6, 79245-79253. [CrossRef]

33. Nziko, V.D.P.; Scheiner, S. Comparison of $\pi$-hole tetrel bonding with $\sigma$-hole halogen bonds in complexes of $\mathrm{XCN}(\mathrm{X}=\mathrm{F}, \mathrm{Cl}, \mathrm{Br}, \mathrm{I})$ and $\mathrm{NH}_{3}$. Phys. Chem. Chem. Phys. 2016, 18, 3581-3590. [CrossRef]

34. Liu, M.X.; Li, Q.Z.; Li, W.Z.; Cheng, J.B.; McDowell, S.A.C. Comparison of hydrogen, halogen, and tetrel bonds in the complexes of HArF with $\mathrm{YH}_{3} \mathrm{X}(\mathrm{X}=$ halogen, $\mathrm{Y}=\mathrm{C}$ and Si). RSC Adv. 2016, 6, 19136-19143. [CrossRef]

35. Voronkov, A.M.G.; Grebneva, E.A.; Trofimova, O.M.; Chernov, N.F.; Albanov, A.I.; Chipanina, N.N. The unusual reaction of phenyltrifluorosilane with 2-aminoethanol and its N-methyl derivatives. Doklady Chem. 2006, 409, 139-141. [CrossRef]

36. Voronkov, M.G.; Trofimova, O.M.; Grebneva, E.A.; Chernov, N.F.; Abzaeva, K.A. Phenyltrifluorosilane in organoelemental and organic synthesis. Rus. J. Gen. Chem. 2011, 81, 2391-2411. [CrossRef]

37. Martin, D.; Hauthal, H.G. Dimethyl Sulphoxide; John Wiley \& Sons: New York, NY, USA, 1975.

38. Frisch, M.J.; Trucks, G.W.; Schlegel, H.B.; Scuseria, G.E.; Robb, A.; Cheeseman, J.R.; Scalmani, G.; Barone, V.; Mennucci, B.; Petersson, G.A.; et al. Gaussian 09, RevisionD.01; Gaussian Inc.: Wallingford, CT, USA, 2009.

39. Boys, S.F.; Bernardi, F. The calculation of small molecular interactions by the differences of separate total energies. Some procedures with reduced errors. Mol. Phys. 1970, 19, 553-566. [CrossRef]

40. Serebryanskaya, T.V.; Novikov, A.S.; Gushchin, P.V.; Haukka, M.; Asfin, R.E.; Tolstoy, P.M.; Kukushkin, V.Y. Identification and $\mathrm{H}(\mathrm{D})$-bond energies of $\mathrm{C}-\mathrm{H}(\mathrm{D}) \cdots \mathrm{Cl}$ interactions in chloride-haloalkane clusters: A combined X-ray crystallographic, spectroscopic, and theoretical study. Phys. Chem. Chem. Phys. 2016, 18, 14104-14112. [CrossRef] [PubMed]

41. Ivanov, D.M.; Kinzhalov, M.A.; Novikov, A.S.; Ananyev, I.V.; Romanova, A.A.; Boyarskiy, V.P.; Haukka, M.; Kukushkin, V.Y. $\mathrm{H}_{2} \mathrm{C}(\mathrm{X})-\mathrm{X} \cdots \mathrm{X}^{-}(\mathrm{X}=\mathrm{Cl}, \mathrm{Br})$ halogen bonding of dihalomethanes. Cryst. Growth Des. 2017, 17, 1353-1362. [CrossRef]

42. Novikov, A.S.; Gushchin, A. Trinuclear molybdenum clusters with sulfide bridges as potential anionic receptors via chalcogen bonding. Cryst. Eng. Comm. 2021, 23, 4607-4614. [CrossRef]

43. Ivanov, D.M.; Kirina, Y.V.; Novikov, A.S.; Starova, G.L.; Kukushkin, V.Y. Efficient $\pi$-stacking with benzene provides $2 \mathrm{D}$ assembly of trans-[PtCl $\left.2\left(\mathrm{p}_{2}-\mathrm{CF}_{3} \mathrm{C}_{6} \mathrm{H}_{4} \mathrm{CN}\right)_{2}\right]$. J. Mol. Struct. 2016, 1104, 19-23. [CrossRef]

44. Abramov, P.A.; Novikov, A.S.; Sokolov, M.N. Interactions of aromatic rings in the crystal structures of hybrid polyoxometalates and Ru clusters. Cryst. Eng. Comm. 2021, 23, 6409-6417. [CrossRef]

45. Bulat, F.A.; Toro-Labbé, A.; Brinck, T.; Murray, J.S.; Politzer, P. Quantitative analysis of molecular surfaces: Areas, volumes, electrostatic potentials and average local ionization energies. J. Mol. Model. 2010, 16, 1679-1691. [CrossRef] [PubMed]

46. Reed, A.E.; Curtiss, L.A.; Weinhold, F. Intermolecular interactions from a natural bond orbital, donor-acceptor viewpoint. Chem. Rev. 1988, 88, 899-926. [CrossRef]

47. Bader, R.F.W. Atoms in Molecules. In A Quantum Theory; Oxford University Press: New York, NY, USA, 1990.

48. Bader, R.F.W. AIM2000 Program, v. 2.0; McMaster University: Hamilton, ON, Canada, 2000.

49. Del Bene, J.E.; Alkorta, I.; Elguero, J. Pnicogen-bonded complexes $\mathrm{H}_{\mathrm{n}} \mathrm{F}_{5-\mathrm{n}} \mathrm{P}: \mathrm{N}-\mathrm{b} a s e$, for $\mathrm{n}=0-5$. J. Phys. Chem. A 2014, 118, 10144-10154. [CrossRef] [PubMed]

50. Del Bene, J.E.; Alkorta, I.; Elguero, J. Influence of substituent effects on the formation of P...Cl pnicogen bonds or halogen bonds. J. Phys. Chem. A 2014, 118, 2360-2366. [CrossRef]

51. Alkorta, I.; Sánchez-Sanz, G.; Elguero, J.; Del Bene, J.E. Exploring $\left(\mathrm{NH}_{2} \mathrm{~F}\right)_{2}, \mathrm{H}_{2} \mathrm{FP}: \mathrm{NFH}_{2}$, and $\left(\mathrm{PH}_{2} \mathrm{~F}\right)_{2}$ potential surfaces: Hydrogen bonds or pnicogen bonds? J. Phys. Chem. A 2013, 117, 183-191. [CrossRef]

52. Schütz, M.; Brdarski, S.; Widmark, P.O.; Lindh, R.; Karlström, G. The water dimer interaction energy: Convergence to the basis set limit at the correlated level. J. Chem. Phys. 1997, 107, 4597-4605. [CrossRef]

53. Bauzá, A.; Mooibroek, T.J.; Frontera, A. Non-covalent $\mathrm{sp}^{3}$ carbon bonding with $\mathrm{ArCF}_{3}$ is analogous to $\mathrm{CH}-\pi$ interactions. Chem. Commun. 2014, 50, 12626-12629. [CrossRef]

54. Bauzá, A.; Quiñonero, D.; Frontera, A.; Deyà, P.M. Substituent effects in halogen bonding complexes between aromatic donors and acceptors: A comprehensive ab initio study. Phys. Chem. Chem. Phys. 2011, 13, 20371-20379. [CrossRef]

55. Bondi, A. Van der Waals volumes and radii. J. Phys. Chem. 1964, 68, 441-451. [CrossRef]

56. Lipkowski, P.; Grabowski, S.J.; Robinson, T.L.; Leszczynski, J. Properties of the C-H $\cdots \mathrm{H}$ dihydrogen bond: An ab initio and topological analysis. J. Phys. Chem. A 2004, 108, 10865-10872. [CrossRef]

57. Shchavlev, A.E.; Pankratov, A.N.; Borodulin, V.B.; Chaplygina, O.A. DFT study of the monomers and dimers of 2-pyrrolidone: Equilibrium structures, vibrational, orbital, topological, and NBO analysis of hydrogen-bonded interactions. J. Phys. Chem. A 2005, 109, 10982-10996. [CrossRef] [PubMed] 
58. Grimme, S.; Mück-Lichtenfeld, C.; Erker, G.; Kehr, G.; Wang, H.; Beckers, H.; Willner, H. When do interacting atoms form a chemical bond? Spectroscopic measurements and theoretical analyses of dideuteriophenanthrene. Angew. Chem. Int. Ed. 2009, 48, 2592-2595. [CrossRef] [PubMed]

59. Bader, R.F.W. Bond paths are not chemical bonds. J. Phys. Chem. A 2009, 113, 10391-10396. [CrossRef]

60. D'Oria, E.; Novoa, J.J. On the hydrogen bond nature of the C-H ․ F interactions in molecular crystals. An exhaustive investigation combining a crystallographic database search and ab initio theoretical calculations. Cryst. Eng. Comm. 2008, 10, 423-436. [CrossRef]

61. Arnold, W.D.; Oldfield, E. The chemical nature of hydrogen bonding in proteins via NMR: J-couplings, chemical shifts, and AIM theory. J. Am. Chem. Soc. 2000, 122, 12835-12841. [CrossRef]

62. Alkorta, I.; Elguero, J.; Del Bene, J.E. Pnicogen bonded complexes of $\mathrm{PO}_{2} \mathrm{X}(\mathrm{X}=\mathrm{F}, \mathrm{Cl})$ with nitrogen bases. J. Phys. Chem. A 2013, 117, 10497-10503. [CrossRef]

63. Bauzá, A.; Ramis, R.; Frontera, A. A combined theoretical and cambridge structural database study of $\pi$-hole pnicogen bonding complexes between electron rich molecules and both nitro compounds and inorganic bromides $\left(\mathrm{YO}_{2} \mathrm{Br}, \mathrm{Y}=\mathrm{N}, \mathrm{P}\right.$, and As). J. Phys. Chem. A 2014, 118, 2827-2834. [CrossRef]

64. Solimannejad, M.; Ramezani, V.; Trujillo, C.; Alkorta, I.; Sánchez-Sanz, G.; Elguero, J. Competition and interplay between $\sigma$-hole and $\pi$-hole interactions: A computational study of 1:1 and 1:2 complexes of nitryl halides $\left(\mathrm{O}_{2} \mathrm{NX}\right)$ with ammonia. J. Phys. Chem. A 2012, 116, 5199-5206. [CrossRef]

65. Sánchez-Sanz, G.; Trujillo, C.; Solimannejad, M.; Alkorta, I.; Elguero, J. Orthogonal interactions between nitryl derivatives and electron donors: Pnictogen bonds. Phys. Chem. Chem. Phys. 2013, 15, 14310-14318. [CrossRef] [PubMed]

66. Guo, X.; Li, Q.Z.; Xiao, B.; Yang, X.; Li, W.Z.; Cheng, J.B. Influence of F and Se substitution on the structures, stabilities and nature of the complexes between $\mathrm{F}_{2} \mathrm{CSe}$ and $\operatorname{HOX}(\mathrm{X}=\mathrm{F}, \mathrm{Cl}$, Br, and I). RSC Adv. 2015, 5, 52667-52675. [CrossRef]

67. Kirchner, B.; Reiher, M. The secret of dimethyl sulfoxide-water mixtures. A quantum chemical study of 1DMSO-nwater clusters. J. Am. Chem. Soc. 2002, 124, 6206-6215. [CrossRef]

68. Cumming, J.B.; Kebarle, P. Summary of gas phase acidity measurements involving acids AH. Entropy changes in proton transfer reactions involving negative ions. Bond dissociation energies $\mathrm{D}(\mathrm{A}-\mathrm{H})$ and electron affinities $\mathrm{EA}(\mathrm{A})$. Can. J. Chem. 1978, 56, 1-9. [CrossRef]

69. Espinosa, E.; Molins, E.; Lecomte, C. Hydrogen bond strengths revealed by topological analyses of experimentally observed electron densities. Chem. Phys. Lett. 1998, 285, 170-173. [CrossRef] 